\title{
ENURESIS
}

\section{A BRIEF REVIEW, A TENTATIVE THEORY AND A SUGGESTED TREATMENT}

\author{
BY \\ R. SESSIONS HODGE and H. M. HUTCHINGS \\ From the Neuropsychiatric Department, Musgrove Park Hospital, Taunton
}

(RECEIVED FOR PUBLICATION APRIL 25, 1952)

The problem of nocturnal enuresis is constantly before us. Few syndromes present in the clinic with greater frequency; few have a more extensive literature; few are more baffling. What follows here makes no pretence to be an exhaustive study but is rather a brief review with a tentative theory of the neurophysiology of enuresis and a suggestion for treatment arising from this.

'Essential enuresis' has been defined (Crosby, 1950 ) as ' the involuntary and unconscious voiding of urine after 5 years of age in the absence of significant congenital or acquired defect or disease of the nervous or urogenital systems and in the absence of significant psychological defects. ...' With this definition we are in general agreement but would recognize that many workers would find difficulty in accepting the whole of it.

Any assessment of the incidence of enuresis in the general population is difficult. The memorandum on enuresis prepared by a Joint Committee of the B.M.A. and the Magistrates' Association (1948) suggests that one in seven of the population has at some time suffered from nocturnal enuresis. It has been suggested (Braithwaite, 1950) that $5 \%$ of all children are not dry by 5 years of age, and the percentage of enuretics at children's clinics has been assessed (Crosby, 1950; Kanner, 1948) as 26\%; with this last figure we are in general agreement.

The mechanism of micturition has received much attention (Barrington, 1914, 1933; Denny-Brown and Robertson, 1933) but, as Crosby points out, the study of micturition alone will not permit an understanding of urinary continence and suggests that there must occur inhibition of micturition in order that it may not occur too early in answer to an increasing bladder volume, and, in the case of the sleeper, that this inhibition must remain prepotent over stimuli tending to initiate micturition until the discomfort of a full bladder wakes the subject.

It is probable that the physiology of urinary continence has not yet been fully apprehended or explained; as Clark (1945) says, "The experimental evidence on the encephalic control of the bladder is so contradictory that a theoretical explanation is impossible until further work is available.'

\section{Causation}

The causation of this disorder is also a matter of dispute. There would appear to be agreement on the two main divisions, organic and functional, but Nash (1947) points out that between the extremes of cases of gross maltraining and obvious functional origin and those of frank infection or organic nervous disease lies a morass of undiagnosed cases.

Kanner (1948) in listing the causative factors considers that the organic factors, spina bifida and local irritation, account for very few cases but notes that $7 \%$ of his enuretics were epileptic. He considers that depth of sleep, though considerable in many enuretics, was not abnormally so and notes some light sleepers among his patients. He does, however, draw attention to the influence of training and parental attitudes, suggesting that the overprotective mother encourages persistent dependency in the child, which may be reinforced by the physician's concurrence in the theory of 'weak bladder' or ' weak kidneys'.

Other workers have stressed the importance of ' toilet training' and Gill (1940), who estimated that $4 \%$ to $5 \%$ of all children evacuated to Brighton were enuretic, considered that low social standards were a causative agent.

The psychogenic factors in enuresis have been discussed by Mowrer and Mowrer (1938), who quote the theories of Freud, Sodger and Campbell in support of urinary eroticism and McGuiness in support of nocturnal enuresis as an aggressive act in a submissive child, and conclude that

\footnotetext{
' the veritable barrage of prohibition and injunction constituting the socialization of the growing child in our culture is inevitably frustrating ... and it is not surprising that resentments and hostilities which are thus thrust underground crop up in strange places and weird guises.'
} 
Shlionsky, Sarracino and Bischof (1945) found in a study of 100 male enuretics that 83 gave a childhood history of emotional and personality problems, neurotic traits and habit disorders in addition to enuresis. In $14 \%$ of these there was a definite history of juvenile delinquency.

Michaels and Goodman (1938), in stressing the importance of recognizing that enuresis is one facet of a disturbed personality, suggest that while delinquency reflects a disturbance in culture, personality integration and maturation with sociopsychological manifestations, enuresis reflects a disturbance in psychobiological integration and maturation with physiological manifestations.

Huschka (1943) in his study of a group of 215 problem children found that of 79 with a history of enuresis 50 had never been able to establish micturitional control. He considers this an interesting finding in view of the conclusion of Michaels and Goodman (1938) that enuresis of this character is a prototype of psychopathic personality.

Some support for the 'psychopathic' theory comes from Stalker and Band (1946), quoting Michaels and Secunda (1944), who reported that electroencephalographic abnormalities were common in children with behaviour disorders and enuresis but not in such children without enuresis. Stalker and Band consider that the E.E.G. and cystometrographic findings link enuresis with personality in its fullest neuro-psychiatric sense.

Depth of sleep and its influence on nocturnal enuresis have engaged the attention of many workers. Braithwaite (1950) considers that the combination of detrusor achalasia and deep sleep produces nocturnal enuresis. Cook (1950) considers the questions of depth of sleep to be paramount, as does Lombardini, Heilpern and Morrison (1948), while Ström-Olsen (1950) found that of 28 enuretic adults 25 were abnormally heavy sleepers and obtained good results with large doses of amphetamine sulphate. Perli (1949) administered phenamine and eserine with an injunction to micturate once only in the night 'to train the sentinel in the cortex'. Zeltner (1951) administered vitamin $H$ to lighten sleep. Stockwell and Smith (1940) and Courtin (1923) did not, however, consider that their subjects slept any more soundly than the normal, while Helsborg (1950) in a series of electroencephalographic studies obtained at the moment of bed-wetting considered that the findings were not in accord with the theory that nocturnal enuresis occurs during unusually deep sleep or that it accompanies nocturnal minor epileptic attacks. We would, however, stress the fact that a history of both nocturnal enuresis and encopresis should immediately give rise to a suspicion of epilepsv with nocturnal attacks
It will be seen that more than one worker has emphasized the concept that enuresis, though frequently a presenting feature, is yet on investigation to be considered as a factor in a personality pattern, and Stalker and Band drew attention to the correlation between enuresis and psychopathic states, suggesting that the same lack of inhibitory control is seen physiologically in the enuretic and emotionally and socially in the psychopath.

Malavazos (1935) and Nittis (1939) consider that immaturity of the genito-urinary organs is a causative factor in the disorder, and Schultz and Anderson (1943) agree with this. Winsbury-White (1941) in a study of 310 cases of enuresis found that in $98 \%$ there was a history of one of the exanthemata but in only $16 \%$ was it established that the enuresis was consequent. Of 220 cases examined by cystoscopy, $70 \%$ showed inflammation of the trigone and internal urinary meatus, and of $\mathbf{1 7 3}$ examined by posterior urethrography, $76 \%$ showed posterior urethritis. While by no means exhaustive the foregoing may serve to indicate the diversity of suggested causative agents.

\section{Familial Incidence}

Cohen (1947) finds that in the social and personal histories of enuretics a familial incidence is frequently found and mentions an extreme case of 11 enuretic siblings and an enuretic father. We are in general agreement and can cite three instances of enuresis occurring in families for three generations: in one instance members of all three generations inhabit the same house and all nine siblings in the third generation are enuretic. Treatment of this family was discontinued owing to the bland indifference with which our instructions and suggestions were received.

\section{Treatment}

Treatment of enuresis has ranged from the barbaric to the recondite, each succeeding generation deploying such weapons as were from time to time available. An impressive list (Mowrer and Mowrer, 1938) includes innumerable drugs; hormones; special diets; restriction of fluids; voluntary exercises in urinary control; injections of physiological saline, sterile water, paraffin and other inert substances; the passage of a bougie; cantharides plaster applied to the pubis; cauterization of the neck of the bladder; spinal punctures; tonsillectomy, circumcision, clitoridotomy; high-frequency mechanical vibration and electrical stimulation of various parts of the body; prostatic massage; bladder and rectal irrigation; roentgen and other forms of irradiation; chemical neutralization of 
urine; sealing or constriction of urinary orifice; hydrotherapy; local freezing of external genitalia by ice or 'chloratyl '; elevation of the foot of the patient's bed; sleeping on the back; not sleeping on the back; clamps, rubber sacks etc.; hypnotism; suggestion; ringing of bell by conduction effected by a damp pad; and the ingestion of a fat mouse skinned and cooked in a pie. This last remedy, which might surely have been described by F. M. R. Walshe as ' hallowed by time-and by nothing else' is known by one of us (R.S.H.) to have been administered in this locality quite recently.

Good results have been claimed for certain specific measures. Winsbury-White (1941) claims that $97 \%$ of patients benefited by urethral dilatation. Stockwell and Smith (1940), in their study of 100 cases, considered causation to be $13 \%$ organic, $37 \%$ neuromyogenic and $50 \%$ psychogenic. As well as correcting physical defects and simple training they employed for the 'spastic bladder' atropine therapy plus aqueous distension, for the 'atonic bladder' stimulation of the neck of the bladder and in seven cases acetylbetamethylcholine, and for the strongly expulsive bladder of small capacity simple and regular aqueous distension. Those with a psychogenically determined disability responded well to psychotherapy and resolution of personal and social problems. Their results indicated $64 \%$ cured and $21 \%$ improved.

Lechler (1950), in discussing the relationship of sleep to enuresis, concludes that the sleep of the enuretic differs from the deep sleep of fatigue. He draws attention to the frequency of 'micturitional dreams' amongst enuretics and suggests that the enuretic ' feels' the stimulus of a full bladder, but is puzzled that the subject should fail to respond by awakening. 'Enureticus Senex' (Lancet, 1951) describes in his letter a typical 'micturition dream" and we are again in general agreement that this is tolerably frequent amongst enuretics. This writer, however, makes the important observation that the passage of urine into the urethra resulted in closure of the sphincter and instant awakening.

Schachter (1950) describes the methods of Pacifico (1947), Poloni and Abba (1949 and 1950) and others in the treatment of enuresis by 'lumbo-pubic shock' with $80-110$ volts at $200-500$ milliamps $\frac{1}{10}$ second. Some $40 \%$ to $70 \%$ cures were claimed but the treatment was described as 'painful'.

Breitländer (1950), considering that enuresis in the majority of cases is due to a disturbance of the correlation between sympathetic and parasympathetic innervation, after excluding primary nervous disorder and organic causes, irradiated the small pelvis with superficial doses of $100 \mathrm{r} / \mathrm{o}$. Later he irradiated the 'cerebrum' from lateral temporal fields $6 \times 8 \mathrm{~cm}$. with two doses of $100 \mathrm{r} / \mathrm{H}$ (estimated for the hypophysis) at a week's interval.

Zeltner (1951) claims good results from the exhibition of para-aminobenzoic acid and vitamin $\mathrm{H}$.

Of all the foregoing we have no experience and can make no comment upon the methods.

Kittredge and Brown (1944) describe the use of 'ephredine' and claim good results from its nightly exhibition and this is supported by Lombardini et al. (1948). We have been unable to obtain confirmation of this in our series.

Schultz and Anderson (1943), Kugelmass (1947) and Cioffari and Clark (1947) all discuss enuresis. in terms of delayed maturation of the genitourinary system and claim satisfactory results following the exhibition of gonadotropic hormone or testosterone given by the intradermal, subcutaneous. or intramuscular routes or by inunction. In our hands this approach to the problem has not produced the same satisfactory results.

Davidson and Douglass (1950) modified the 'Mowrer bed' (Mowrer and Mowrer, 1938) and obtained $75 \%$ cures with its use.

Crosby (1950) in an admirable paper points out that the age incidence curve of enuresis shows that more than $50 \%$ of the children who are enuretic at 4 years of age will be dry by 10 years and thus warns against the claim of ' cure' when long periods of treatment are needed. He considers that essential enuresis is not primarily a symptom but an entity or state arising from physiological activity. He goes on to discuss an intriguing method of treatment which aims at extinguishing any conditioned responses which initiate micturition and at reinforcing the natural method of building up the inhibitory tone. This last was achieved by the use of (1) urine electrodes (male and female pattern) for determining the onset of micturition, (2) a sensitive relay, (3) stimulating electrodes for providing an adjustable stimulus, (4) a generator of signals to the observer, (5) a source of E.M.F. One drop of urine is sufficient to operate the relay which then operates circuits to the observer by light and sound and a stimulus of variable intensity to the skin of the loin region of the patient. Very satisfactory results were obtained.

Nash (1949) after reviewing the many factors in causation advises a re-educative régime which involves day time micturition every quarter-hour with the interval gradually extended. A high percentage of good results is claimed. Dott (1947) also advocates a day time training programme which shall anticipate the distension of the bladder and ensure complete empyting.

Huschka (1943) in a study of 215 problem children considered that our knowledge of the 
optimum age at which training in voluntary control should be started is still inadequate and quotes Gesell's studies of development. It was concluded from this that of enuretics over 3 years of age 28 had been trained in a coercive manner, and that a study of 59 children who had responded undesirably to coercive training showed that in $92 \%$ training had begun before the age of 10 months. The views of Michaels on the genesis of urethral sadism and psychopathic personality are discussed.

McGraw (1940), in an interesting study of identical twins, investigated the sequential changes in behaviour which accompany and denote the development of voluntary control of micturition and studied the effect of an early systematic training schedule upon the ultimate achievement of bladder control-whether it accentuates, distorts or is ineffectual in influencing the general course of development of this order. Briefly, she found that in twin C.D., who was given no training until 430 days of age, the 'success rating' was only $10 \%$ lower from the beginning than that of twin P.D. who was 'trained' from 23 days. Twin Hi.P. went ' untrained' to 2 years of age and his 'success rating' was slightly above that of twin $\mathrm{Hu}$. P. trained from 41 days. A satisfactory response to training was not apparent in trained twins P.D. and Hu.P. until from 320-360 days and it is suggested that the full response could not be expected to begin before 530 days. The author goes on to discuss the studies of Tilney (1937) and Conel (1939) on the structural development of the brain and offers an interpretation of the irregular responses of the 'trained twins' up to the age of 20 months, suggesting that the sharp response and subsequent stabilization 'indicates the actual functioning of the maturing process of discrimination and generalization'. To this very interesting concept we shall return later.

\section{Present Study}

The present study is based on work done on 131 cases. All these cases were referred to the child guidance clinics of Somerset County Council between November, 1945, and December, 1950.

All were seen, examined and treated during clinic sessions and no special enuretic clinic was held. In consequence it was not always possible to see individual cases as frequently as might have been deemed desirable nor was it always possible to provide the specific therapy, e.g. play therapy, appropriate to certain cases. Our specific form of therapy developed to its present form over a period of time. This plasticity of approach to the problem has made the assessment of results more difficult. But it is perhaps proper to stress here that the work and this report derive from the ordinary day-to-day preoccupations of a busy clinic and was not conceived or planned as a specific research project.

We propose to discuss our findings under certain headings.

Age of Referral. This extended from 4 years to 18 years, with the highest number of referrals at $5,6,7$ and 8 years with a peak at 7 years.

Sex Incidence. There were almost exactly twice as many boys as girls.

Intelligence. The distribution of intelligence was similar to that in the general child population, the curve taking the usual form with a peak at I.Q. 90.

Family History. In some cases in this series the family history was not obtainable but in 39 cases $(30 \%)$ there was a family history of enuresis and in an additional 10 cases a history of neuropathy.

Depth of Sleep. In 65 cases $(50 \%)$ there was a history of 'heavy' or 'very heavy' sleep.

Occurrence of Enuresis. In 103 cases the enuresis was entirely nocturnal. In five it was diurnal only and in 23 both diurnal and nocturnal.

Analysis of Causal Factors. Since many ' causes ' for enuresis have been adduced we considered the group under these headings:

BREAKDOWN. These were patients with a history of having been dry at night for a year or more and then becoming enuretic. On further investigation two were considered to be epileptic. In 29 others the symptoms were considered to be due to psychological stresses resulting in subsequent regressive behaviour.

Primarily Psychologically Determined. In this group of 23 cases the precipitating cause was considered to be primarily psychogenic. Thus in 52 cases a psychological disturbance was considered to be a factor of importance.

Primarily 'Faulty Adaptation'. The neuropathology of this group will be discussed later. In it are included 52 cases. In 13 additional cases it was considered that psychological stress had been superimposed on a cerebral integration which showed 'faulty adaptation' (i.e. ' mixed' cases).

EPILEPTIC. Five cases were considered to be epileptic by clinical and electroencephalographic criteria.

Faulty Training. This in our view accounted for three cases.

Mental Deficiency. Two cases were found on investigation to be mentally defective.

Spina Bifida and Hypospadias. One case.

Electroencephalography. The E.E.G. records of 27 of these children were taken, using a six-channel recorder with bipolar electrodes and standard placement. 
The five patients mentioned above who were diagnosed as epileptic on clinical grounds showed E.E.G. records acceptable beyond reasonable doubt as 'of the epileptic type suggesting a liability to both major and minor seizures'. All five were given appropriate anticonvulsant therapy.

The 22 other records all showed in greater or lesser degree an abnormality which should perhaps at this stage be described as non-specific but outside the normal range for the child's age. Fourteen of these records showed this in severe degree, eight in lesser degree.

While this phenomenon can hardly be discussed in detail in this paper, we will hazard a suggestion that it may well indicate a delayed or impaired cerebral adaptation such that adequate inhibitory mechanism does not occur. Persistence of this cerebral inadequacy, if the postulate be accepted, may result in any individual in a degree of vulnerability of the central nervous system such that it is incapable of dealing with more than a critical number of signals and responds to an excess by breakdown and reversion to a more primitive state.

Some such hypothesis may perhaps go some way to further understanding of the epilepsies, may elucidate further the problem of nocturnal enuresis (and we would again draw attention to the phenomenon of ' sleep activation in epilepsy '), and may even throw a little light on some of the complexities of persistent aberrant social conduct.

With the exception of the five patients diagnosed as epileptic, in whom the referral note gave enuresis as one presenting symptom, the reason for referral in all the other cases was simply bed-wetting.

Treatment. We have employed two methods, psychiatric and by drugs.

Psychiatric. Our practice here probably differs little from that in other child guidance clinics.

Lack of staff and long waiting-lists have made it impossible to give adequate play therapy to all who would appear to have needed it, but a combination of advice to parents, easing of school difficulties, admission to one of our hostels for maladjusted children and the use of the appropriate drug has been our usual routine in cases where there has been a demonstrable psychopathological factor regarded as of primary importance.

We would, however, stress the point that enuresis alone can and does create a 'psychopathological state' within a home. The attendant discomfort, work and nuisance in itself creates tension between mother and child, and, in at least one of our cases referred for severe obsessional handwashing and found on enquiry to be enuretic, the response of the enuresis to drug therapy was followed in an excep- tionally short time by cessation of the ritualistic behaviour.

In all but four of these primarily psychological cases drugs were used.

One case only has been classed as a complete failure; there was a severe breakdown of the motherchild relationship amounting to complete, and apparently irremediable, rejection of the child by her mother.

The case of hypospadias and spina bifida has been taken on by a surgical colleague. Readers familiar with the Düss Projection Test will be intrigued by the patient's reply to story six (the toy elephant) . . . ' 'cos his front was up the back and his back was up the front!'

Drug TREatment. This began in the early stages of this investigation and the present method of administration has gradually evolved. The drug used is amphetamine sulphate.*

The mother is provided with a card on which she records daily ' wet ', ' dry' or ' less wet', this last being of considerable importance. The drug is administered in $5 \mathrm{mg}$. tablets, beginning with such a dose as one tablet at bedtime followed by two tablets at $10-10.30$ p.m. when the child is lifted to micturate. The dose is varied according to response. A child who is habitually wet when lifted-some, though few, showed this-may need as many as three or four tablets at bedtime and a correspondingly increased dose at 10 p.m.

The heaviest dosage, given to a very dull girl, was four tablets at bedtime and six at 10 p.m. In only three cases have we had to discontinue treatment owing to the child being unable to take the drug as restlessness was too severe. No cardiac disability or reaction has been observed and very few have complained of seriously reduced appetite. When the 10 p.m. dose has had to be increased and restlessness has been disturbing 'seconal', gr. $\frac{3}{4}$, has been added and the amphetamine sulphate continued.

Several interesting points have been observed. A child will commonly 'dry up' gradually. The parent's comment may be, 'It's only a little spot now', or 'only pyjamas damp in the morning', whereas previously the amount voided produced such a description as 'a bedful', 'a swamp'. There may be a critical threshold in dosage below which the bed is wet, above which it is dry. Thus one intelligent adolescent who was keeping his own record noted that he was dry on seven tablets, wet on six.

\footnotetext{
* We desire to record our indebtedness to Messrs. Menley and James, and in particular to Dr. W. R. Bett for the personal interest and kindliness he has shown, for supplying large quantities of 'benzedrine' and also for the necessary inert tablets made in the same mould for use in our control group.
} 
Other comments by parents have been, ' He's so much better in himself-more lively ', ' doing better at school'.

Finally we draw attention to the magnitude of the dose which we have found possible to give with good results.

Control Group. Sixteen enuretics were given inert tablets at the beginning of their treatment. Of these 11 failed to respond at all; their enuresis was unchanged. Two showed little or no change. One, always a variable enuretic, continued variable. Two improved. Both were 'breakdown' cases and psychopathological factors were present. One however, said that on (inert) tablets he could now ' wake himself up'.

In six cases inert tablets were substituted during treatment. When receiving inert tablets there was in all six cases a sudden or gradual regression to the original enuretic state, which improved again with amphetamine sulphate. One boy was treated from February to August (with his mother's full connivance and cooperation) with repeated substitution of inert for active tablets. With the exception of one unexplained night when he was dry while receiving inert tablets he was invariably wet on inert, dry on active tablets.

We are reasonably satisfied that the improvement obtained was due to the exhibition of amphetamine sulphate in appropriate doses as described above.

ANALysis of Results

\begin{tabular}{|c|c|c|}
\hline State of Case at End of Treatment & No. & $\%$ \\
\hline 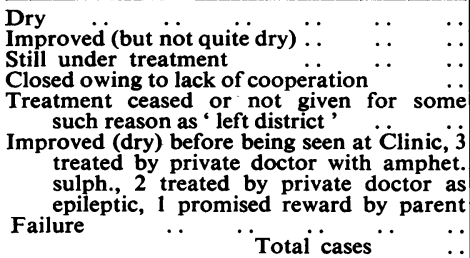 & $\begin{array}{l}44 \\
14 \\
23 \\
24 \\
19\end{array}$ & $\begin{array}{l}34 \\
11 \\
17 \\
18 \\
\\
14\end{array}$ \\
\hline
\end{tabular}

Average Length of Treatment. The average was 10 months, and applies to those cases closed dry and treated by drug treatment only or mainly by drug treatment. If it had been possible to see all cases as often as once fortnightly and adjust the dose to meet the patient's response this time might well have been shortened.

\section{The Theory of ' Faulty Adaptation'}

In offering this tentative contribution to the understanding of the mechanism of nocturnal enuresis we have been influenced not only by our own findings but by the work of many others.

Briefly we postulate that nocturnal enuresis is an example of the failure, or delay, of the cerebral adaptive mechanisms primarily affecting the thalamo-reticular relay to Brodmann's area 24 (caudal end of the cingulate gyrus). The suggested connexions have been described by Dusser de Barenne and McCulloch (1941) and Glees (1944), and the intrathalamic diffusion system by McLardy (1951). We arrive at this concept from our study of the E.E.G. findings in our series and from consideration of the work of Gibbs and Gibbs (1947) on 'sleep activation' on the E.E.G. recording in epileptics, this in spite of Helsborg's (1950) comment.

In support of this postulate we note again Crosby's insistence on the control of micturition as being an inhibitory function, Stalker and Band's comment on the lack of inhibitory control in the enuretic and the psychopath, and Gesell's, Michaels' and McGraw's studies on the age factor and micturition levels in the training of infants. We observe also that Higgins, Williams and Nash (1951) state that 'evidence is accumulating which associates disturbance of micturition with particular areas of the brain ... ' and later, ' whether a child wakes up when the bladder is full or continues to sleep so that the bladder empties itself automatically depends upon the intensity of the afferent impulse, the condition of the cortical reception and the intensity of the subsequent inhibition impulse.'

From this we proceed to consider Grey Walter's (1950) recent work on learning circuits and observe that he finds that no less than seven distinct operations must be performed in establishing a connexion between different stimuli to achieve a conditioned response. In the same author's article (1951) 'Activity Patterns in the Human Brain ' he reminds us that amongst the complex organic pattern of ten thousand million nerve cells which go to make up the nervous system of man lies 'a fringe of uncertain function' which is associated with simplicity and also with a high degree of adaptability and plasticity, and goes on to remind us that " to deal with uncertainty is the principle function of the higher centres '.

Recalling again McGraw's (1940) phrase 'the actual functioning of the maturing process of discrimination and generalization ', the observation of 'Enureticus Senex' on his immediate reaction to stimulation of the urethra and our own observation that, under treatment by amphetamine sulphate, many children dry up gradually, voiding only a small quantity before inhibitory activity contracts the external sphincter, we suggest that the essential enuretic provides an example of delayed cerebral maturity and consequent inability readily to effect the appropriate learning circuits.

This concept of delayed or impaired cerebral 
adaptive mechanism may well reach beyond the study of nocturnal enuresis : already work is nearing completion, in which we have been concerned, which suggests that the concept is applicable to other types of aberrant and 'immature' behaviour. We would, however, point out that at this stage the concept should rank only as a working hypothesis subject to much further investigation, consideration and criticism.

Professor Amedeo Marrazzi, of the American Army Chemical Centre, informs us that his work on the effect of amphetamine sulphate on the central nervous system leads him to consider that its action 'produces a true primary inhibition at all sympathetic synapses just as it does at many sympathetic neuroeffector junctions'. In the central nervous system he considers that the 'action of amphetamine must either be due to a mixed central action, i.e. inhibitory (on mono- and multi-synaptic pathways) and excitatory somewhere else or to an inhibitory action with release of lower centres from higher control. We have not found our subjects to be predominantly parasympatheticotonic and consider that the action is probably 'excitatory somewhere else' and that a more generalized effect occurs, such as was described by Serota (1939) in his studies on cerebral temperature fluctuation. Professor Marrazzi hopes to clear this last point through his work on labelled benzedrine with in vivo counting of radioactivity.

We suggest that cerebral adaptation may be facilitated by the action of amphetamine sulphate via the thalamo-cortical diffusion relay. We suspect that the relay may be adversely affected by such conditions as intercurrent infection (and our records support this) and facilitated, at any rate for a period, by heightened emotional tonus.

Finally we submit that these suggestions may offer not only a mode of therapy but perhaps throw a little light on another aspect of personality integration.

We record herewith our grateful thanks to Dr. J. F. Davidson, O.B.E., Medical Officer of Health Somerset County Council, for the use of case material, Miss G. E. Neal, Senior Psychiatric Social Worker Somerset County Council, for the very full part which she took in the treat- ment of these cases, and finally to Mrs. J. S. R. Ronald, Slape Manor, Dorset, for her generous financial help, without which this and much other work of this Department would never have been done at all.

\section{REFERENCES}

Barrington, F. J. F. (1914). Quart. J. exp. Physiol., 8, 33. - (1933). Brain, 56, 126.

Braithwaite, J. V. (1950). Practitioner, 165, 273.

Breitländer, K. (1950). Strahlentherapie, 82, 307.

Cioffari, M. S. and Clark, H. G. (1947). Arch. Pediat., 64, 61.

Clark, G. (1945). Urol. cutan. Rev., 49, 612.

Cohen, D. L. (1947). J. Urol., Baltimore, 57, 331.

Conel, J. LeRoy (1939). The Postnatal Development of the Human Cerebral Cortex. Cambridge, Mass.

Cook, E. N. (1950). J. Amer. med. Ass., 144, 1421.

Courtin, W. (1923). Arch. Kinderheilk., 73, 40.

Crosby, N. D. (1950). Med. J. Aust., 2, 533.

Davidson, J. R. and Douglass, E. (1950). Brit. med. J., 7, 1345.

Denny-Brown, D. and Robertson, E. G. (1933). Brain, 56, 149.

Dott, E. F. (1947). Archives of Disease in Childhood, 22, 182.

Dusser de Barenne, J. G. and McCulloch, W. S. (1941). J. Neurophysiol., 4, 304.

Gibbs, E. L. and Gibbs, F. A. (1947). Res. Publ. Ass. nerv. ment. Dis., 26, 366.

Gill, S. E. (1940). Brit. med. J., 2, 199.

Glees, P. (1944). J. Anat., Lond., 78, 47.

Helsborg, H. C. (1950). Ugeskr. Laeg., 112, 256.

Higgins, T. T., Williams, D. I. and Nash, D. F. E. (1951). Analogy of Childhood. London.

Huschka, M. (1943). Psychosom. Med., 5, 254.

Joint Committee of B.M.A. and Magistrates' Assoc. (1948). Memorandum on Enuresis, B.M.A. London.

Kanner, L. (1948). Child Psychiatry, 2nd ed., p. $428 . \quad$ Oxford.

Kittredge, W. E. and Brown, H. G. (1944). New Orleans med. Surg. J., 96, 562.

Kugelmass, I. N. (1947). N.Y. St. J. Med., 47, 1369.

Lancet (1951). 1, 803. (Letter signed 'Enureticus Senex'!)

Lechler, H. (1950). Neue med. Welt, 1, 1338.

Lombardini, V. B., Heilpern, R. and Morrison, J. R. (1948). Northw med., Seattle, 47, 805 .

McGraw, M. B. (1940). J. Pediat., 16, 580.

McLardy, T. (1951). Electroenceph. Clin. Neurophysiol., 3, 183.

Malavazos, A. (1935). Urol. cutan. Rev., 39, 322. Michaels, J. J. and Goodman, S. E. (1938). Arch. Neurol. Psychiat.,
Chicago, 40, 699.

- and Secunda, L. (1944). Amer. J. Psychiat., 101, 407.

Mowrer, O. H. and Mowrer, W. M. (1938). Amer. J. Orthoppsychiat., 8, 436.

Nash, D. F. E. (1947). Practitioner, 159, 188.

(1949). Ann. roy. Coll. Surg. Engl., 5, 318.

Nittis, S. (1939). Univ. Hosp. Bull. Ann. Arbor, 5, 59

Pacifico, A. (1947). Cervello, 23, 401.

Perli, P. D. (1949). Sovetsk. Med., No. 8, p. 35.

Poloni, A. and Abba, G. C. (1949). Minerva med., Torino (Pt. Sci.), 40 (1), 317.

(1950). Ibid., 41 (1), 307.

Schachter, M. (1950). J. Méd. Chir. Prat., 121, 219.

Schultz, F. W. and Anderson, C. E. (1943). J. clin. Endocr., 3, 405.

Serota, H. M. (1939). J. Neurophysiol., 2, 42.

Shlionsky, H., Sarracino, L. R. and Bischof, L. J. (1945). War Med., Chicago, 7, 297.

Stalker, H. and Band, D. (1946). J. ment. Sci., 92, 324

Stockwell, L. and Smith, C. K. (1940). Amer. J. Dis. Child., 59, 1013. Ström-Olsen, R. (1950). Lancet, 2, 133.

Tilney, F. (1937). The Structure and Development of the Brain. Unpublished Lecture, New York, May 21, 1937.

Walter, W. Grey (1950). Ministry of Supply, Proceedings. Symposium on Information Theory, pp. 134-136. London.

(1951). Aspects of Form, ed. L. L. Whyte, pp. 179-195. London.

Winsbury-White, H. P. (1941). Brit. J. Urol., 13, 149.

Zeltner, C. (1951). Méd. et Hyg., Genève, 9 (No. 187), 41. 